\title{
(2) OPEN ACCESS \\ Invaluable role of histopathology in the diagnosis of cutaneous leiomyosarcoma in insulin injection site reaction
}

\author{
Kathleen Renee Lundeberg (D) ,' Laura J Vidis, ${ }^{1,2}$ Jennifer Martin, ${ }^{3}$ \\ Julie Randolph-Habecker ${ }^{4}$
}

${ }^{1}$ Student Physician, Pacific Northwest University of Health Sciences College of Osteopathic Medicine, Yakima, Washington, USA

${ }^{2}$ Department of Pathology \& Laboratory Medicine, Dartmouth-Hitchcock Medical Center, Lebanon, New Hampshire, USA

${ }^{3}$ School of Occupational Therapy, Texas Woman's University, Dallas, Texas, USA ${ }^{4}$ Department of Biomedical Sciences, Pacific Northwest University of Health Sciences College of Osteopathic Medicine, Yakima, Washington, USA

\section{Correspondence to} Kathleen Renee Lundeberg; klundeberg94@gmail.com

Accepted 11 October 2021

\section{Check for updates}

(c) BMJ Publishing Group Limited 2021. Re-use permitted under CC BY-NC. No commercial re-use. See rights and permissions. Published by BMJ.

To cite: Lundeberg $K R_{\text {, }}$ Vidis LJ, Martin J, et al. BMJ Case Rep 2021;14:e241333. doi:10.1136/bcr-2020241333

\section{SUMMARY}

Soft tissue sarcomas (STSs) are rare and may often be misdiagnosed, resulting in delays in treatment. A 67-year-old cisgender woman with type 2 diabetes mellitus and obesity presented to her primary care physician with a mass on her left proximal arm. The clinical opinion of the attending physician was that of an insulin injection site reaction. After further evaluation from the physician, the patient was diagnosed with a lipoma without confirmatory histology. The patient continued to present with an enlarging mass, decline in health status and continued with local wound care. The patient underwent a confirmatory biopsy following which, the patient was diagnosed with leiomyosarcoma. This case report highlights the case of a person with a low or moderate income with a self-reported low health literacy living in a rural community and how STS may be misdiagnosed in medically underserved. The patient's primary or oncology care team are not involved in the production or review of this case report.

\section{BACKGROUND}

Clinical outcomes of obesity and type 2 diabetes mellitus (T2DM)-related complications can be further worsened by culture, race and geographical location. ${ }^{1}$ WHO data indicate that approximately $50 \%$ of the world's population lives in rural and remote areas while most healthcare workers live and work in cities. ${ }^{2}$ The Association of American Medical Colleges predicts that the USA will face a deficit of 46000-90000 physicians by $2025 .^{3}$ This physician shortage is particularly concerning in rural areas where the shortage leads to overburdened staff and further exacerbates health disparities. ${ }^{45}$ Moreover, the current COVID-19 pandemic exposed how being on low or moderate income (LMI), with T2DM, low health literacy, obesity and reduced access to quality healthcare increased a patient's morbidity and mortality. ${ }^{67}$

Leiomyosarcomas (LMSs) are rare soft tissue cancer, accounting for $5 \%-10 \%$ of soft tissue sarcomas (STSs), capable of developing in multiple organs originating from muscle, fat and blood vessels. ${ }^{8}$ These tumours are most commonly formed at five distinct anatomic sites: (1) retroperitoneum, (2) deep extremity, (3) uterus, (4) blood vessels and (5) superficial dermis. ${ }^{8}$ Cutaneous LMS arise from the piloerector muscles in the skin, gastrointestinal LMS from the smooth muscle in the GI tract or a blood vessel, uterine LMS from the smooth muscle in the uterine muscular layer and retroperitoneal from the tunica media of a blood vessel. LMS is considered a subtype of spindle cell sarcoma and resemble smooth muscle cells with atypia and increased mitoses, unlike benign leiomyomas. ${ }^{9}{ }^{10}$ Cutaneous LMS presents as slow growing and either as a circumscribed nodular tumour or a poorly defined induration of the skin. ${ }^{11}$ According to Begum and Hossain, the standard guidelines recommend performing a soft tissue ultrasound scan to confirm the mass and show the plane of the mass. ${ }^{12}$ Ultrasonography has been found to be more sensitive compared with palpation for identifying lipohypertrophy (98\% and $70 \%$, respectively). ${ }^{13}$ In addition, executing an immunohistochemistry (IHC) of a biopsy sample of the mass would reveal prominently actin positive, desmin positive and is CD34 negative. ${ }^{14}$ Specifically, the CD34 staining would be able to distinguish cutaneous LMS from lipomas, which are strongly positive for CD34. ${ }^{15}$ Using these standardised approaches when suspecting a cutaneous LMS would lend to a more accurate differential diagnosis. ${ }^{16}$ This case study is one example of the repercussions of the underlying challenges of the US healthcare system in a medically underserved community negatively impacting a person on LMI.

\section{CASE PRESENTATION}

A 67-year-old cisgender woman with T2DM and obesity presented to her primary care physician with a mass on her left proximal arm (figure 1). Her history of poorly controlled T2DM was exacerbated by challenges in continuity of healthcare due to her rural location and further compounded by socioeconomic factors, including poverty and access to appropriate nutritional support. The patient first noticed the lump on her arm 4 years before attending her family physician with this complaint (figure 2). The lump was situated at the site of where she injected herself with insulin. The patient described the lump as soft, non-painful and had been gradually increasing in size. At that point, a clinical diagnosis of lipoma was made by the primary care physician without biopsy or histological confirmation to exclude malignancy or infection. Due to a combination of lack of resources in the rural setting and limited patient health literacy, no further action was taken at that time. Subsequently, the mass increased in size and rapidly enlarged becoming firm and painful. Imaging was 


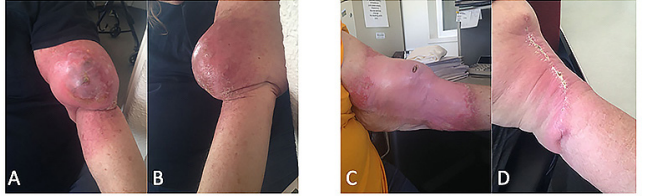

Figure 1 Prior to rupture of the tumour due to intralesional pressure $(A, B)$, postrupture $(C)$ and postsurgical resection (D).

ultimately obtained, with an ultrasound and MRI revealing a mass suspicious for neoplasia. The patient attributes this delay from presentation to diagnostic imaging to limited access to quality healthcare resources in her rural community due to financial constraints, physical accessibility and miscommunication between members of her healthcare team.

The mass grew to approximately $12 \times 15 \mathrm{~cm}$, causing purple discolouration and skin breakdown (figure 1). The patient's pain had become more pronounced, radiating up her neck, with additional numbness and tingling in the tips of her four fingers and thumb. Open biopsy followed, confirming a highgrade pleomorphic spindle cell sarcoma. The mass was Murine Double Minute 2 (MDM2) negative, which indicated it was not a dedifferentiated liposarcoma. The patient's care team, which is not involved in the production of this case report, did not perform any additional IHC to further characterise the tumour at that time. Copious hematoma-like fluid was also obtained, and reaccumulated in the surgical cavity at the primary tumour site. A CT pulmonary angiogram was negative for metastases, and she received a course of preoperative radiotherapy. Shortly after radiotherapy, the tumour filled with fluid and erupted due to pressure, prompting urgent surgical resection of the mass (figure 1).

The histopathology report of the resection described a $12.5 \times 8.3 \times 5.4 \mathrm{~cm}$ tumour, of which $60 \%$ was considered postradiation necrotic material. Microscopically, the tumour was pleomorphic, with spindle cell features and high-grade cytological atypia and high mitotic activity. CD34 levels were not assessed. Malignant samples were strongly positive for SMA and desmin, and negative for S-100, CD31, AE1/AE3, CD10 and MNF116, classifying the tumour as a high-grade LMS, with pathological staging of ypT3. The margins were uninvolved, but the surrounding soft tissue was oedematous and fibrotic, with areas of haemorrhage and necrosis.

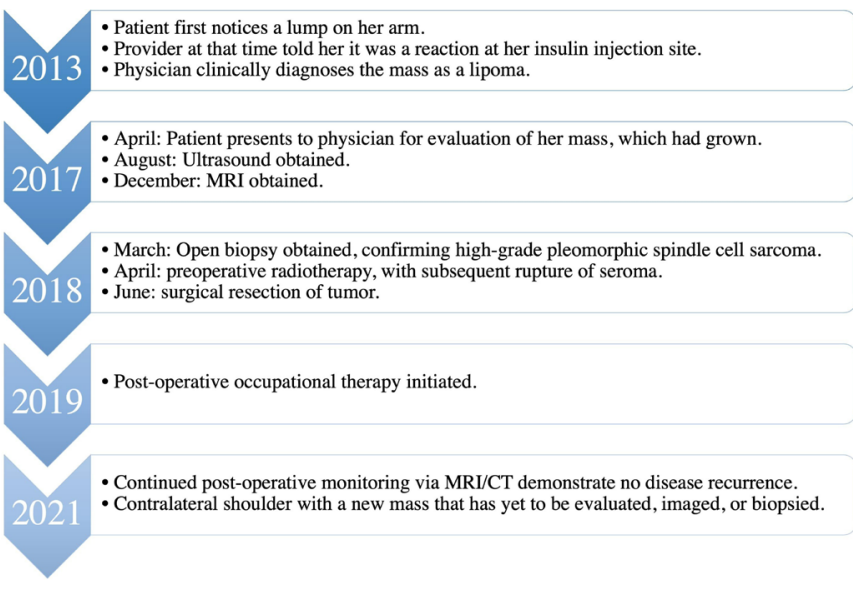

Figure 2 Timeline outlining the patient's clinical presentation, treatment and outcomes.
The patient engaged in postoperative outpatient occupational therapy (OT), where an occupational analysis and subsequent care plan addressing the patient's barriers to postsurgical care was conducted. The care plan involved the person, environment and occupation by addressing the underlying diseases of T2DM and obesity. The focus of OT was her activities of daily living as well as supportive services needed to address the patient's current concerns relative to engaging in daily life. Moreover, the OT provided physical rehabilitation including lymphoedema management, scar mobilisation and strengthening of the affected arm. On discharge postoperative outpatient OT, the patient obtained satisfactory strength and range of motion in the affected arm which allowed her to return to work and maintain independent living.

Multiple MRI and CT imaging postresection demonstrated no recurrence of disease. Since her last primary care visit, the patient developed a similar mass on her contralateral shoulder and it has yet to be evaluated, imaged, or biopsied. The patient continues to reside in a rural, medically underserved area, with the nearest urban healthcare resources approximately $225 \mathrm{~km}$ (140 miles) away. Her ongoing socioeconomic and medical access barriers have been compounded by COVID-19 and continued to delay her follow-up care. The patient endured psychosocial despair and limited social support during COVID-19. As a result, the patient was unable to again obtain timely follow-up diagnostics.

\section{GLOBAL HEALTH PROBLEMS LIST}

1. Increase of T2DM and obesity in rural USA and low-income and middle-income countries (LMIC).

2. Lack/delay of accessible medical care in rural USA and LMIC.

3. Health literacy and agency for patients living in rural areas.

\section{Global health problem analysis} Increase of T2DM and obesity in rural USA and LMIC

Rates of obesity continue to rise in the USA and globally. Initially, urbanisation was thought to be an important root of this increase; however, higher obesity prevalence is seen in rural communities when compared with urban areas in the USA as well as many other countries. ${ }^{17} 18$ Consequently, there is a rising disparity in the incidence and treatment of obesity-related disorders, including T2DM, in rural communities as compared with urban communities. The rate of T2DM in rural America is about $17 \%$ higher than in urban areas. ${ }^{19}$ In addition, mortality related to T2DM is almost $3-5$ times higher in rural areas. ${ }^{20}$ Factors contributing to this increased mortality include being on LMI, limited access to endocrinology specialists, mistrust of larger urban healthcare facilities and providers, and lack of transportation. $^{21} 22$ Globally, T2DM and T2DM-related morbidity and mortality rates in rural communities increased markedly, especially with COVID-19. ${ }^{23} 24$ The COVID-19 pandemic underscored how the combination of being on LMI, diabetic, rural, low health literacy and obesity are a recipe for worsening clinical outcomes in LMIC compared with rural areas in high-income countries (HIC). ${ }^{25}$

The patient described in this case report attended her primary care clinic every 6 months for the management of her diabetes. She had a different provider every visit, which limited her continuity of care. She obtained her insulin from her local pharmacy, outside of the clinic she was seen for her diabetes. Furthermore, the patient lived alone and was solely responsible for injecting herself. The patient's mass was first noticed by a phlebotomist during a routine blood test. The phlebotomist recommended that the patient seek medical evaluation of the non-healing mass. 
Lack/delay of accessible medical care in rural USA and LMIC

The aetiology of the LMS should not be the focal point of this case study. The focus here is on differentiating a lipoma versus LMS using standardised approaches. Correct diagnosis and effective treatment were delayed in this patient because of the multifactorial failures in US healthcare system and lack of support for people on LMI. According to the World Bank and WHO, half of the world's population does not have access to essential health services. ${ }^{26}$ In addition, rural US communities experience other barriers to healthcare disproportionally, including increased distance travelled to access healthcare services, lack of reliable transportation, poor health literacy, social stigma and privacy concerns. ${ }^{27}$ Rural areas are often medically underserved lacking both primary and specialist care clinicians and other healthcare workers. $^{2829}$ Brouns et al reported doctor delay occurred in 27 of 100 patients with the most frequent reason being a misdiagnosis from the start, leading to no or inadequate investigation. ${ }^{30}$ The main reason for patient delay in STSs was attributed to the lack of specific and severe symptoms. Of the total incorrect initial diagnoses of lipoma, none were misdiagnosed as LMS. Those initially diagnosed as a lipoma were finally diagnosed as a liposarcoma and synovial sarcoma. ${ }^{30}$

\section{Histopathology services}

Cutaneous LMS can only be confirmed via histopathological examination, making IHC an instrumental tool in arriving at a definitive diagnosis. ${ }^{31}$ Histopathology is an essential part of healthcare and must be accessible to ensure effective medical care. From diagnosis and staging through guiding and monitoring treatment, every step requires the support of histopathology investigations. Many regions, however, including those considered HIC, face an extreme shortage of histopathology services. ${ }^{32}$ Rural US communities are faced with closing rural hospitals and their associated laboratory medicine and histopathology support. While a few centres in LMIC have adequately equipped laboratories, most have poor infrastructure, are inadequately equipped and experience shortages of trained personnel and pathologists. ${ }^{33} 34$ Pathologist availability in sub-Saharan Africa, for example, is less than one per 500000-1 million people, compared with more than 60 per million in the USA. ${ }^{35}$ Scarcity of histopathology services in these regions results not only in frequent misdiagnoses but also long turn-around times, both of which may hinder appropriate and timely treatment of patients. Thway and Fisher found that most of the major discrepancies were due to differing opinions in categorisation, suggesting that unfamiliarity of pathologists with certain tumours is a major contribution to diagnostic discrepancies; whereas no discrepancies were reported between a lipomas and LMS. ${ }^{36}$

Our patient's mass was not biopsied at initial or subsequent presentation, but ultimately addressed when the mass began causing symptoms secondary to mass-effect and severely compromising her quality of life. In the medically underserved community this patient resides in, there are no STS specialists, nor are histopathological services readily available.

\section{Radiological imaging}

Even in LMICs, ultrasound scan is often the first modality used when imaging a soft tissue lipoma because it is inexpensive, available and relatively sensitive and specific. However, the fibrous capsule in superficial lipomas cannot be appreciated on ultrasound of intramuscular lipomas because the capsule cannot be distinguished from the muscle that envelops it. ${ }^{37}$ Studies have shown that access to radiology services are disproportionally lower in rural and small hospitals in the USA. One contributing factor is related to difficulty in recruiting and retaining radiologists. The lack of rural radiologists can lead to an inability to meet the service demands when compared with non-rural healthcare centres. ${ }^{38} 39$ To address this issue, significant effort is being placed on developing teleradiology services in rural areas. Interestingly, the COVID-19 pandemic has allowed institutions to explore teleradiology, evaluate the technological limitations, and address regulatory concerns that appear to be the main barriers to using technology more widely in rural communities. ${ }^{40}$

The patient resides in a rural, medically underserved community, where radiology services are limited due to the overall patient burden on the healthcare system. The patient reported that scheduling her radiology appointments and the limited technical skill of radiology technicians in obtaining adequate imaging served as additional barriers to her diagnostic workup and ultimately delay in her care. These additional barriers to care exacerbate the social determinants of health that already had complicated her access to healthcare.

\section{Access to specialist care}

Just as access to radiology and pathology healthcare providers creates challenges for rural patients, access to specialised oncology care is also an issue. Approximately 20\% of the US population resides in rural areas, but only $3 \%$ of oncologists practice in these areas, and over $70 \%$ of USA counties do not have oncologists. ${ }^{41}$ Rural patients with cancer tend to be diagnosed later and have higher mortality. ${ }^{42}$ In 2019 , the American Society of Clinical Oncology found that rural patients are less likely to receive stand-of-care treatment, follow-up or supportive services than urban patients. ${ }^{43}$ This disparity can further compound the treatment of rare cancers such as STSs.

There is one comprehensive cancer centre with a multidisciplinary sarcoma team to serve five states in the Pacific Northwest. While this centre is only 150 miles from our patient's location, poverty, lack of transportation, poor health literacy and difficulty navigating urban areas precluded her from readily taking advantage of the expertise at this centre.

\section{Interaction between STS specialist centres and rural healthcare providers}

There have been several strategies purposed to address the challenges of rural cancer care. Rural oncology clinics can partner with larger urban cancer centres to provide access to oncologists and allow patients to receive treatments, such as chemotherapy, closer to home. ${ }^{44}$ Again, telehealth options for conferencing with cancer specialists or having virtual tumour boards may allow rural oncology clinics to provide an elevated level of care. ${ }^{45-47}$ These solutions often require complex coordination, training, access to broadband internet and differing state regulations. Finally, while reimbursement for telemedicine services is possible through Medicare and Medicaid, the payments may be limited and it may be unclear as to how to divide the payments to collaborating institutions. ${ }^{48}$

\section{Health literacy and agency for patients living in rural areas}

This case report focuses on an LMS clinically misdiagnosed as a lipoma. While LMSs are rare malignant sarcomas, the reasons for a delay in diagnosis are regrettable. The barriers of rural medicine and access to care for patients with LMI, T2DM, and obesity are crucial global concerns. The emotional and stressful toll of the patient not being believed that something was seriously wrong independently worsened the quality of her life. This case clearly demonstrates the 
need for accountability to standardised protocols and a call to action for all members of the healthcare team as bestowers of quality care for all.

Health literacy is seen as the cognitive and social skills that motivate and enable individuals to gain access to healthcare and allow them to understand and use information to maintain good health. ${ }^{49}$ If the patient had a high level of health literacy and was engaged in patient-centred care regarding her T2DM practices, the attending physician would have ascertained that the patient rotated injection sites, rested the affected site and performed the injection technique accurately. ${ }^{50}$

\section{Patient's perspective}

Before I was diagnosed with cancer, my local doctors were not quite sure what was wrong. The tumour on my arm kept growing for 3 years and my doctors kept telling me it was a fatty tumour. Finally, the nurse who draws my blood said I needed to see a specialist because the tumour was becoming large and hard. She told another co-worker at that time and I got a call the same day referring me to Seattle to see a cancer specialist but it is very hard for me to travel there. In order to travel the 3 hours to Seattle, I need to take time off work, save money for gas, and schedule a ride with my sister and brother-in-law. Once I was seen by the cancer specialist, I felt like I was treated very well. They gave me many tests and a treatment plan. My treatment took place at my local cancer centre, so I did not need to travel to Seattle. The cancer teams in Yakima and Seattle worked really well together. I received radiation first to try to shrink the tumour before surgery. While receiving radiation, my tumour filled with fluid and it burst. The cancer doctor in Yakima quickly communicated with my doctor in Seattle and they scheduled my surgery immediately.

The hardest part of this whole process has been a lack of follow through with insurance, imaging departments, other medical professionals, office workers, and schedulers. More than once, I would have an MRI, ordered by my cancer doctor, only to find out it was incorrect or incomplete. I would then have to have another MRI to make up for the incorrect one. Each time, I would have to wait for results, take time off from work, wait for an open appointment, and pay out-of-pocket for the co-payments. In terms of scheduling, often weeks would go by without an appointment or I would be scheduled with another doctor who did not know anything about me. Sometimes it felt like the office helpers had an attitude and did not want to work with other schedulers or offices. I think everyone needs to remember that patients trust receptionists and other healthcare members and everyone should work together.

My advice to doctors and medical students is: know who your helpers are. Know who works for you and know what they do and do not do for your patients. Those that are working with you need to follow through otherwise your patients will suffer. Also, it is really hard to keep switching primary care doctors. I felt like I fell through the cracks, so please know your workers and trust that they will follow through for your patients when you leave. The whole team needs to work together, like the body, if one part is not working, the whole thing will not work right. People who are in charge of medications, nurses who take blood pressure, and people who clean the exam rooms are all equally important and their role should be recognised. If I can inspire somebody else about the importance of continuity of care, then I will be happy.

\section{Learning points}

- In differentiating a lipoma versus leiomyosarcoma using standardised approaches, imaging, pathological analysis and subsequent immunohistochemistry proved to be critical in the correct diagnosis for this patient.

- While biopsies carry risk, there are specific markers, including CD34, that quickly discern lipomas from a rarer soft tissue sarcoma.

- This case report illustrates how a person with a low or moderate income, type 2 diabetes mellitus, low health literacy, obesity and reduced access to quality healthcare agency may unnecessarily increase a patient's morbidity and mortality.

Several studies have found that rural populations have a lower health literacy than urban populations. ${ }^{51}$ However, there is a debate as to whether lower health literacy is related to living in a rural location or related to other factors. For example, when known confounders were controlled for, some studies no longer found a difference in health literacy between urban and rural individuals. ${ }^{52}$ Factors that can negatively impact an individual's health literacy include living in poverty, lower level of education, race/ethnicity, age and disability. ${ }^{53}$

Acknowledgements Thank you, Dr. Michele McCarroll, for your invaluable contribution to this team in the process of compassionately capturing this patient's story. We are also grateful for the time and insight from Dr. Frank Curtis in the review of this manuscript.

Contributors KRL: Researched the case and participated in writing the manuscript, LJV: Researched the case and participated in writing the manuscript; JM: Brought the case to our attention and provided contact to the patient and important clinical perspective; JR-H: reviewed the manuscript.

Funding The authors have not declared a specific grant for this research from any funding agency in the public, commercial or not-for-profit sectors.

\section{Competing interests None declared.}

Patient consent for publication Consent obtained directly from patient(s) Provenance and peer review Not commissioned; externally peer reviewed. Open access This is an open access article distributed in accordance with the Creative Commons Attribution Non Commercial (CC BY-NC 4.0) license, which permits others to distribute, remix, adapt, build upon this work non-commercially, and license their derivative works on different terms, provided the original work is properly cited and the use is non-commercial. See: http://creativecommons.org/ licenses/by-nc/4.0/.

\section{ORCID iD}

Kathleen Renee Lundeberg http://orcid.org/0000-0002-0116-3966

\section{REFERENCES}

1 Cogburn CD, Culture CCD. Culture, race, and health: implications for racial inequities and population health. Milbank Q 2019;97:736-61.

2 World Health Organization. Increasing access to health workers in remote and rural areas through improved retention. In: Global policy recommendations, 2010. ISBN: 9789241564014. http://www.who.int/hrh/retention/guidelines/en/

3 AAMC. The complexities of physician supply and demand. Washington, D.C: IHS Inc, 2015. https://www.aamc.org/media/10886/download

4 Hospital \& Health Networks. Rural physician shortage demands innovative solutions, 2016. Available: http://www.hhnmag.com/articles/6881-rural-physician-shortagedemands-innovative-solutions [Accessed 08 Aug 2017].

5 AAFPORG. Rural practice, keeping physicians in (position paper). Available: http:// www.aafp.org/about/policies/all/rural-practice-paper.html [Accessed 02 Aug 2017].

6 Dunn CG, Kenney E, Fleischhacker SE, et al. Feeding low-income children during the COVID-19 pandemic. N Engl J Med 2020;382:e40.

7 Nicola M, Alsafi Z, Sohrabi C, et al. The socio-economic implications of the coronavirus pandemic (COVID-19): a review. Int J Surg 2020;78:185-93.

8 Singh Z. Leiomyosarcoma: a rare soft tissue cancer arising from multiple organs. Journal of Cancer Research and Practice 2018;5:1-8. 
9 Yang J, Du X, Chen K, et al. Genetic aberrations in soft tissue leiomyosarcoma. Cancer Lett 2009;275:1-8.

10 Fisher C. Spindle cell sarcomas. Surg Pathol Clin 2011;4:721-44.

11 Fields JP, Helwig EB. Leiomyosarcoma of the skin and subcutaneous tissue. Cancer 1981;47:156-69.

12 Begum M, Hossain MS. A case report on cutaneous leiomyosarcoma with review of literatures. J Curr Adv Med Res 2018;4:63-7.

13 Klimontov VV, Lazarev MM, Makhotin AA, et al. Insulin-Induced lipohypertrophy: clinical and ultrasound characteristics. Diabetes mellitus 2018;21:255-63.

14 Al-Daraji W, Husain E, Zelger BG, et al. A practical and comprehensive immunohistochemical approach to the diagnosis of superficial soft tissue tumors. Int Clin Exp Pathol 2009;2:119-31.

15 Zavan B, De Francesco F, D'Andrea F, et al. Persistence of CD34 stem marker in human lipoma: searching for cancer stem cells. Int J Biol Sci 2015;11:1127-39.

16 Ciurea ME, Georgescu CV, Radu CC, et al. Cutaneous leiomyosarcoma - case report. J Med Life 2014;7:270-3.

17 Lundeen EA, Park S, Pan L, et al. Obesity Prevalence Among Adults Living in Metropolitan and Nonmetropolitan Counties - United States, 2016. MMWR Morb Mortal Wkly Rep 2018:67:653-8.

18 NCD Risk Factor Collaboration (NCD-RisC). Rising rural body-mass index is the main driver of the global obesity epidemic in adults. Nature 2019;569:260-4.

19 The burden of diabetes in rural America, 2019. Available: https://www. ruralhealthresearch.org/projects/100002380 [Accessed 21 Jun 2021].

20 Callaghan T, Ferdinand AO, Akinlotan MA, et al. The changing landscape of diabetes mortality in the United States across region and rurality, 1999-2016. J Rural Health 2020;36:410-5.

21 Brundisini F, Giacomini M, DeJean D, et al. Chronic disease patients' experiences with accessing health care in rural and remote areas: a systematic review and qualitative meta-synthesis. Ont Health Technol Assess Ser 2013;13:1-33.

22 Johnston KJ, Wen H, Joynt Maddox KE. Lack of access to specialists associated with mortality and preventable hospitalizations of rural medicare beneficiaries. Health Aff 2019:38:1993-2002.

23 Hwang CK, Han PV, Zabetian A, et al. Rural diabetes prevalence quintuples over twenty-five years in low- and middle-income countries: a systematic review and metaanalysis. Diabetes Res Clin Pract 2012:96:271-85.

24 Satman I, Demirci I, Haymana C, et al. Unexpectedly lower mortality rates in COVID-19 patients with and without type 2 diabetes in Istanbul. Diabetes Res Clin Pract 2021;174:108753.

25 Zabetian A, Sanchez IM, Narayan KMV, et al. Global rural diabetes prevalence: a systematic review and meta-analysis covering 1990-2012. Diabetes Res Clin Pract 2014;104:206-13.

26 The world Health Bank. Tracking universal health coverage: 2017 global monitoring report, 2017December 13, Available: https://www.worldbank.org/en/topic/univ ersalhealthcoverage/publication/tracking-universal-health-coverage-2017-globalmonitoring-report [Accessed 07 Jul 2021].

27 Rural Health Information Hub. Healthcare access in rural communities. Available: https:// www.ruralhealthinfo.org/topics/healthcare-access\#列arriers [Accessed 07 Jul 2021].

28 Uhlenhake E, Brodell R, Mostow E. The dermatology work force: a focus on urban versus rural wait times. J Am Acad Dermatol 2009;61:17-22.

29 van Dis J. MSJAMA. where we live: health care in rural vs urban America. JAMA 2002;287:108

30 Brouns F, Stas M, De Wever I. Delay in diagnosis of soft tissue sarcomas. Eur I Surg Oncol 2003:29:440-5.

31 Bali A, Kangle R, Roy M, et al. Primary cutaneous leiomyosarcoma: a rare malignant neoplasm. Indian Dermatol Online J 2013:4:188-90.
32 Rambau PF. Pathology practice in a resource-poor setting: Mwanza, Tanzania. Arch Pathol Lab Med 2011:135:191-3.

33 University of North Carolina, Sheps Center for Health Services Research. 87 rural hospital closures: January 2010 - present, 2018. Available: http://www. shepscenter. unc.edu/programs-projects/rural-health/rural-hospital-closures [Accessed 07 Jul 2021].

34 Giraldi DM, Garcia E, Kundu I, Edna Garcia MPH, Iman Kundu MPH, et al. Disparities in rural health care: a look at the field of laboratory medicine. Critical Values 2018:11:40-5

35 Sayed S, Lukande R, Fleming KA. Providing pathology support in low-income countries. J Glob Oncol 2015;1:3-6.

36 Thway K, Fisher C. Histopathological diagnostic discrepancies in soft tissue tumours referred to a specialist centre. Sarcoma 2009:2009:1-7.

37 Rahmani G, McCarthy P, Bergin D. The diagnostic accuracy of ultrasonography for soft tissue lipomas: a systematic review. Acta Radiol Open 2017;6:205846011771670

38 Friedberg EB, Corn D, Prologo JD, et al. Access to interventional radiology services in small hospitals and rural communities: an ACR membership Intercommission survey. J Am Coll Radiol 2019:16:185-93.

39 Cook PS. The challenges of providing interventional radiology services to rural and smaller community hospitals. AJR Am J Roentgenol 2018;211:744-7.

40 Hanna TN, Steenburg SD, Rosenkrantz AB, et al. Emerging challenges and opportunities in the evolution of teleradiology. AJR Am J Roentgenol 2020:215:1411-6

41 Kirkwood MK, Bruinooge SS, Goldstein MA, et al. Enhancing the American Society of clinical oncology workforce information system with geographic distribution of oncologists and comparison of data sources for the number of practicing oncologists. J Oncol Pract 2014:10:32-8.

42 Henley J, Anderson RN, Thomas CC. Invasive cancer incidence, 2004-2013, and deaths, 2006-2015, in nonmetropolitan and metropolitan Counties — United States. MMWR Surveill Summ 2017;66.

43 Levit LA, Byatt L, Lyss AP, et al. Closing the rural cancer care gap: three institutional approaches. JCO Oncol Pract 2020;16:422-30.

44 Ward MM, Ullrich F, Matthews K, et al. Access to chemotherapy services by availability of local and visiting oncologists. J Oncol Pract 2014;10:26-31.

45 Hede K. Teleoncology gaining acceptance with physicians, patients. J Nat/ Cancer Inst 2010:102:1531-3

46 Stevenson MM, Irwin T, Lowry T, et al. Development of a virtual multidisciplinary lung cancer tumor board in a community setting. J Oncol Pract 2013:9:e77-80.

47 Shea CM, Teal R, Haynes-Maslow L, McIntyre M, et al. Assessing the feasibility of a virtual tumor board program: a case study. J Healthc Manag 2014;59:177-93.

48 Satcher RL, Bogler O, Hyle L, et al. Telemedicine and telesurgery in cancer care: inaugural conference at MD Anderson cancer center. J Surg Oncol 2014:110:353-9.

49 Nutbeam D. Health literacy as a public health goal: a challenge for contemporary health education and communication strategies into the 21st century. Health Promot Int 2000;15:259-67.

50 Kalra S, Jawad F. Lipohypertrophy. J Pak Med Assoc 2016:66:779-80

51 Aljassim N, Ostini R. Health literacy in rural and urban populations: a systematic review. Patient Educ Couns 2020;103:2142-54.

52 Zahnd WE, Scaife SL, Francis ML. Health literacy skills in rural and urban populations. Am J Health Behav 2009;33:550-7.

53 Healthy people 2020. Health literacy, 2021. Available: https://www. healthypeople. gov/2020/topics-objectives/topic/social-determinants-health/interventions-resources/ health-literacy

Copyright 2021 BMJ Publishing Group. All rights reserved. For permission to reuse any of this content visit

https://www.bmj.com/company/products-services/rights-and-licensing/permissions/

BMJ Case Report Fellows may re-use this article for personal use and teaching without any further permission.

Become a Fellow of BMJ Case Reports today and you can:

- Submit as many cases as you like

- Enjoy fast sympathetic peer review and rapid publication of accepted articles

- Access all the published articles

Re-use any of the published material for personal use and teaching without further permission

Customer Service

If you have any further queries about your subscription, please contact our customer services team on +44 (0) 2071111105 or via email at support@bmj.com.

Visit casereports.bmj.com for more articles like this and to become a Fellow 